\title{
Dermatoscopic evaluation of alopecia areata
}

\author{
Qasim S. Al Chalabi* , Anfal L. Al harbawi ${ }^{\star}$, Hala N. Al Salman* \\ *Department of Medicine, College of Medicine , University of Mosul , Mosul , Iraq \\ Correspondence: qasimalchalabi@uomosul.edu.iq
}

(Ann Coll Med Mosul 2021; 43 (2):144-151).

Received: $26^{\text {th }}$ Sept. 2021; Accepted: $24^{\text {th }}$ Octo. 2021.

\begin{abstract}
Objective: to assess the dermoscopic characteristics of alopecia areata and their correlations with clinical variants, nail changes, and severity of the disease.

Patients and methods: This is a case-series study, which was carried out on 209 patients with alopecia areata in the Department of Dermatology from January 2020 to January 2021 at Ibn-Sina Teaching Hospital, Mosul, Iraq. After the patient's acceptance to participate in this study, a detailed history was taken. A clinical and dermatological examination was done included hair pulling test, and disease severity was graded according to the severity of alopecia tool (SALT) scoring. Each patch of alopecia areata was examined and assessed using a SKIARY Smartphone Dermatoscope $\odot$, photos were taken and evaluated by three dermatologist experts in dermatoscopy separately and their notes were recorded, evaluated, and tabulated. Spearman`s rank-order correlation test was used for data analysis.

Results: Two hundred and nine patients with alopecia areata had participated in this research. The male to female ratio was 1.5:1. The mean age of presentation was of $21 \pm 10.64$ years. $45 \%$ of the patients had Grade S2 severity. Yellow dots were the most common dermatoscopic finding followed by black dots, while perifollicular scales were the least common. Yellow dots, broken hairs, exclamation mark hairs, and nails changes were correlated with the severe form of the disease $(P<0.05)$.

Conclusion: Alopecia areata has many dermatoscopic manifestations which are helpful in the clinical diagnosis and prognosis of the disease. Yellow dots, black dots, exclamation marks hair, broken hairs, and nail changes are related to the severe form of the disease.
\end{abstract}

Keywords: Alopecia areata, yellow dots, dermatoscopy .

$$
\begin{aligned}
& \text { خاصية التتظير الجلاي لداء الثعلبه } \\
& \text { قاسم سالم الجلبي* ، انفال ليث الحرباوي* ، هالة نذير السلمان }
\end{aligned}
$$

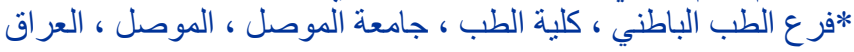

الاهداف : تحديد خصائص المنظار الجلدي (درماتسكوب) في مرض داء الثعلبه وارتباطاتها مع المتغيرات السريرية، وتغيرات

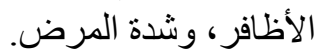

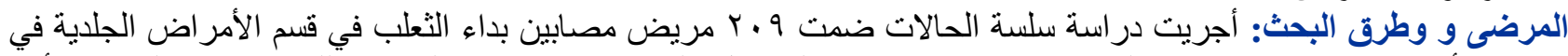

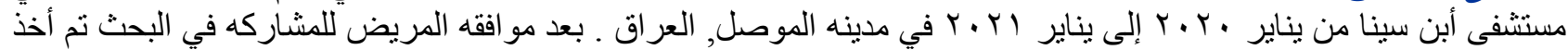

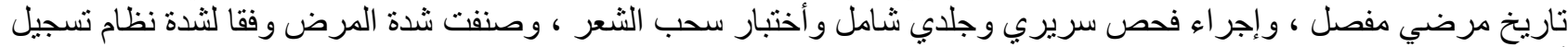

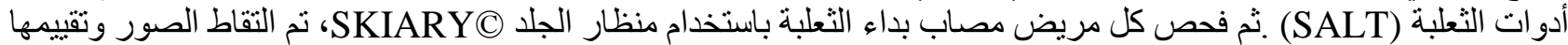

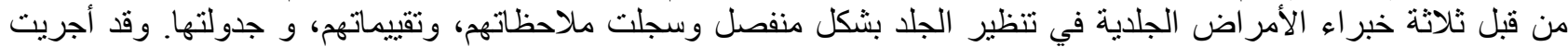

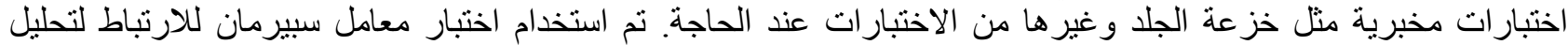
البيانات.

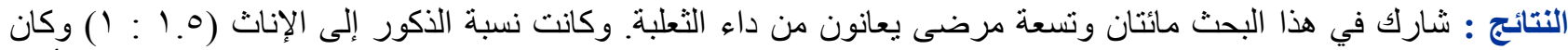

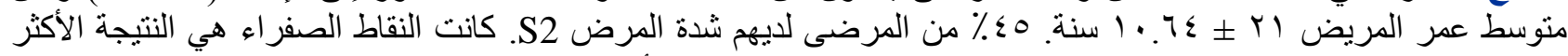

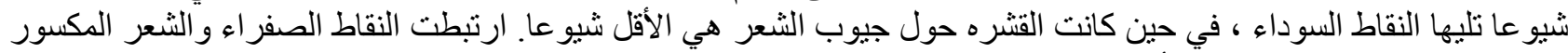

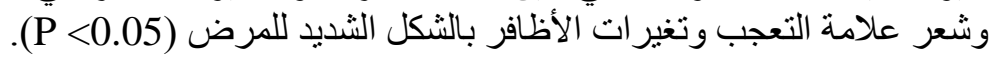




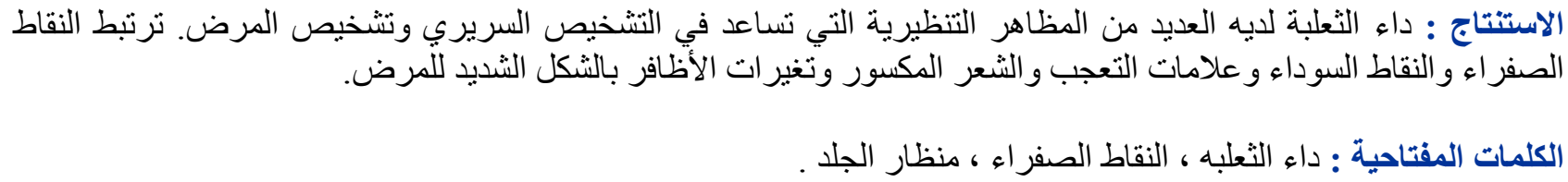

\section{INTRODUCTION}

lopecia areata is one of the commonest autoimmune non-cicatricial hair loss that affects different parts of hair-bearing areas of the body ${ }^{1}$. Nearly 2 percent of the population at some stage of their life may be affected by alopecia areata while the prevalence of alopecia areata was reported to be between $0.1 \%$ to $0.2 \%{ }^{2}$. Both sexes are affected equally and it can occur at any age, although it starts in the first three decades of life in most patients. Alopecia areata can be present clinically as a well-defined patch of hair loss, diffuse hair loss, reticulate hair loss, ophiasis, ophiasis inversus, alopecia totalis (complete loss of scalp hair), or alopecia universalis (hair loss of all over the body) ${ }^{3}$.

The disease can be diagnosed clinically as welldefined round or oval patches of hair loss with apparent smooth normal skin and exclamation point hair at the border of these lesions, unpigmented hairs can be seen scattered throughout the lesion ${ }^{1}$. Nails can be affected in about $10-44 \%$ of alopecia areata patients and it is more common in the severe form of the disease ${ }^{3}$. Alopecia areata is usually associated with pitting of the nails usually fine and stippled; some patients have less well-defined rough accentuated longitudinal ridging of the nail plates (trachyonychia). Other patients may suffer from nail dystrophy that can be the most troublesome aspect of the disease ${ }^{3}$.

Dermoscopy is a non-invasive diagnostic utility used to evaluate many skin and hair disorders ${ }^{4,5}$. Dermoscopy may aid in the diagnosis of many uncertain hair disorders one of them is alopecia areata ${ }^{6}$. Different dermoscopic characteristics are seen in alopecia areata that are already mentioned in other studies such as, black dots (BDs), yellow dots (YDs), tapering hairs (exclamation mark hairs) (EHs), broken hairs (BHs), and short vellus hairs (SVHs) ${ }^{7-10}$,

The association of YDs and other dermoscopic findings with the severe form of the disease were documented ${ }^{7,9}$. However, other studies failed to correlate these dermoscopic findings with the clinical patterns of alopecia areata ${ }^{8,10}$.

Few studies of dermoscopic manifestation of alopecia areata were conducted in Iraq. Therefore, this study was done to determine the dermoscopic characteristics of alopecia areata and their correlations with clinical variants, nail changes, and severity of the disease

\section{PATIENTS AND METHODS}

This is a case-series study, which was carried out on 209 patients with alopecia areata in the Department of Dermatology at Ibn-Sina Teaching Hospital, Mosul, Iraq. The study was conducted from January 2020 to January 2021. Patients were selected randomly. Both sexes and all ages of alopecia areata patients who were willing to provide informed consent were included in this study. Other patients who had cicatricial and noncicatricial hair loss including tinea capitis, tractional alopecia, and androgenetic alopecia were excluded from this study.

A detailed history was taken, clinical and dermatological examinations were done included hair pulling test, and disease severity was graded according to the severity of alopecia tool (SALT) scoring ${ }^{11}$

The severity of alopecia areata was assessed using severity of alopecia tool (SALT) ${ }^{11}$. Scalp hair loss ranged from $\mathrm{S} 1$ to $\mathrm{S} 5$ ( $\mathrm{S} 0=$ no hair loss, S1=less than 25 percent hair loss; S2=26\%-50\% hair loss, S3=51\%-75\% hair loss, S4=76\%-99\% hair loss, S5=total scalp hair loss). The loss of body hair ranged from B0 to B2, where B0 represented no loss, B1 some loss, and B2 complete loss (excluding the scalp), Nail involvement ranged from N0 to N1, N0 represented no nail involvement while $\mathrm{N} 1$ represented nail involvement ${ }^{11}$.

Each patch of alopecia areata was examined and assessed using a SKIARY Smartphone Dermatoscope ${ }^{\odot}$ held by an adaptor on Samsung Note $5^{\odot}$, photos were taken and evaluated by three dermatologist experts in dermatoscopy separately and their notes were recorded, evaluated, and tabulated. Laboratory tests such as skin biopsy and other tests had been performed when required.

\section{Statical Analysis}

Data are presented as mean \pm SD and were analyzed using Spearman`s rank-order correlation test. The data were processed using statistical package $\mathrm{IBM}^{\odot}$ SPSS version 26. 


\section{RESULTS}

Two hundred and nine patients with alopecia areata participated in this study. Males represented $61.3 \%$ (128 patients) of the cases while females represented about $38.8 \%$ (81 patients) with a male to female ratio was 1.5:1. The patient's age was ranged from 3 to 55 years with a mean age of $21 \pm$ 10.6 years. The most common age group affected was 20-29 years which represented $32 \%$ of the patients (Table 1). Duration of illness was varied from 3 weeks to 17 years with a mean \pm SD of 16.8 \pm 3.7 months (duration of illness was less than 6 months in 126 (60.28\%) patients). Family history of alopecia areata was found in 33 (15.78\%) patients.

Table 1. The distribution of alopecia areata according to age groups.

\begin{tabular}{|c|c|c|c|c|c|}
\hline $\begin{array}{c}\text { Age } \\
\text { groups } \\
\text { Years })\end{array}$ & Males & $\begin{array}{c}\text { Female } \\
\mathrm{s}\end{array}$ & $\begin{array}{c}\text { Total } \\
\text { number } \\
\text { of } \\
\text { patients }\end{array}$ & $\begin{array}{c}\text { Percenta } \\
\text { ge }\end{array}$ & $p$-value \\
\hline $1-9$ & 17 & 12 & 29 & $13.9 \%$ & $0.0001^{*}$ \\
\hline $10-19$ & 43 & 21 & 64 & $30.6 \%$ & $0.0001^{*}$ \\
\hline $30-39$ & 24 & 12 & 36 & $17.2 \%$ & $0.0001^{*}$ \\
\hline $40-55$ & 7 & 6 & 13 & $6.2 \%$ & $0.0001^{*}$ \\
\hline Total & 128 & 81 & 209 & $100 \%$ & \\
\hline${ }^{*} p-v a l u e$ & $30.0001^{*}$ & & \\
\hline
\end{tabular}

Multiple patches of alopecia areata (more than 3 patches) were the highest pattern, found in 122 $(58.37 \%)$ patients, while the reticular type was the least common variant (2.8\%). Other clinical patterns of alopecia areata are seen in Table 2.

$45 \%$ of patients had S2 severity according to SALT scoring system, but only 11 (5.3\%) patients had S5 severity. YDs (43.5\%) were the most common finding followed by BDs (33.9\%) and the least sign seen was tulip hairs in 11 (5.3\%) of patients, other dermatoscopic findings are shown in Table 2. Dermatoscopic signs of alopecia areata were seen in Figures 1-3
Table 2. Clinical patterns, the severity of alopecia (SALT scoring), and dermoscopic findings $(n=209)$

\begin{tabular}{|c|c|c|}
\hline Parameters & $\begin{array}{l}\text { Number of } \\
\text { patients }\end{array}$ & Percentage \\
\hline \multicolumn{3}{|l|}{ Clinical pattern } \\
\hline Localized & 62 & $29.6 \%$ \\
\hline Multiple & 122 & $58.4 \%$ \\
\hline Reticular & 6 & $2.8 \%$ \\
\hline Ophiasis & 34 & $16.2 \%$ \\
\hline Sisaphio & 15 & $7.1 \%$ \\
\hline Alopecia totalis & 14 & $6.7 \%$ \\
\hline Alopecia universalis & 11 & $5.3 \%$ \\
\hline \multicolumn{3}{|l|}{ SALT scoring ${ }^{\#}$} \\
\hline S1 & 65 & $31.1 \%$ \\
\hline S2 & 94 & $45 \%$ \\
\hline S3 & 25 & $12 \%$ \\
\hline S4 & 14 & $6 . \%$ \\
\hline S5 & 11 & $5.3 \%$ \\
\hline B1 & 45 & $21.5 \%$ \\
\hline B2 & 11 & $5.3 \%$ \\
\hline No & 181 & $86.6 \%$ \\
\hline $\mathrm{N} 1$ & 28 & $13.4 \%$ \\
\hline \multicolumn{3}{|l|}{$\begin{array}{l}\text { Dermoscopic } \\
\text { findings }\end{array}$} \\
\hline Black dots (BDs) & 71 & $33.9 \%$ \\
\hline Yellow dots (YDs) & 91 & $43.5 \%$ \\
\hline Broken hairs (BHs) & 42 & $20 \%$ \\
\hline $\begin{array}{c}\text { Exclamation mark } \\
\text { hairs (EHs) }\end{array}$ & 43 & $20.5 \%$ \\
\hline $\begin{array}{c}\text { Short vellus hairs } \\
\text { (SVHs) }\end{array}$ & 57 & $27.27 \%$ \\
\hline $\begin{array}{c}\text { Coudability hairs } \\
(\mathrm{CHs})\end{array}$ & 18 & $8.6 \%$ \\
\hline Tulip hairs (THs) & 11 & $5.26 \%$ \\
\hline Pigtail hairs (PTHs) & 28 & $13.4 \%$ \\
\hline Telangiectasia (T) & 27 & $12.9 \%$ \\
\hline $\begin{array}{l}\text { Perifollicular scales } \\
\text { (PS) }\end{array}$ & 15 & $7.1 \%$ \\
\hline \multicolumn{3}{|c|}{$\begin{array}{l}\text { \#SALT: severity of alopecia tool scoring system; } \\
\text { S1-S5: severity of scalp hair loss; B1: partial body } \\
\text { hair loss; B2: complete body hair loss (excluding } \\
\text { the scalp); N0: no nail involvement; N1: nail } \\
\text { involvement. }\end{array}$} \\
\hline
\end{tabular}




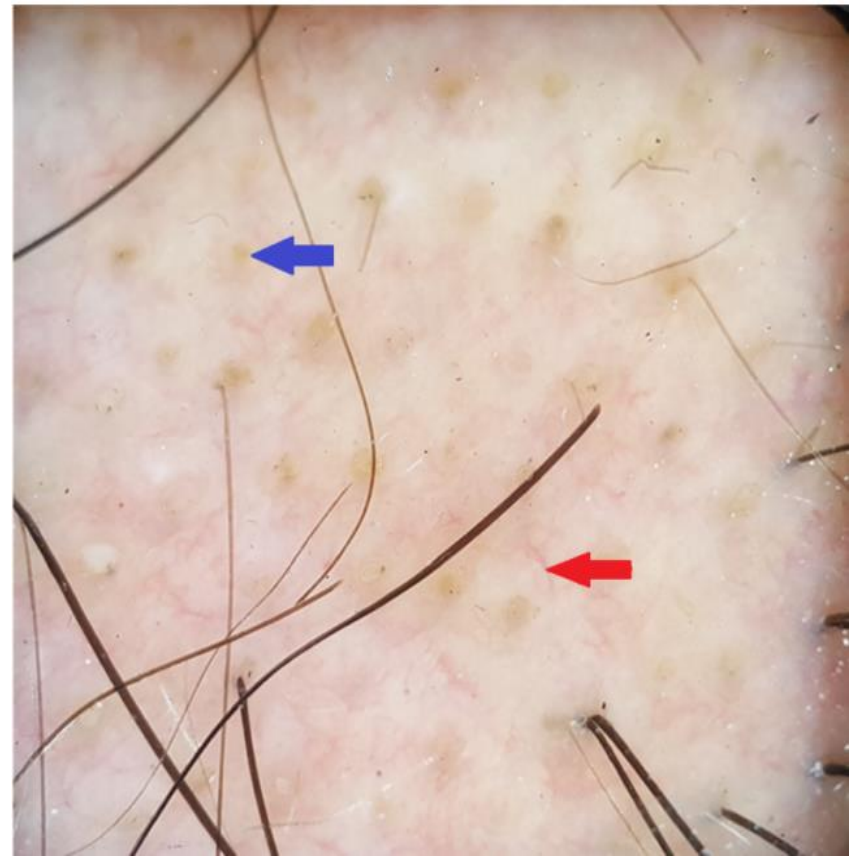

Figure 1. Blue arrow shows yellow dots, red arrow shows telangiectasia.

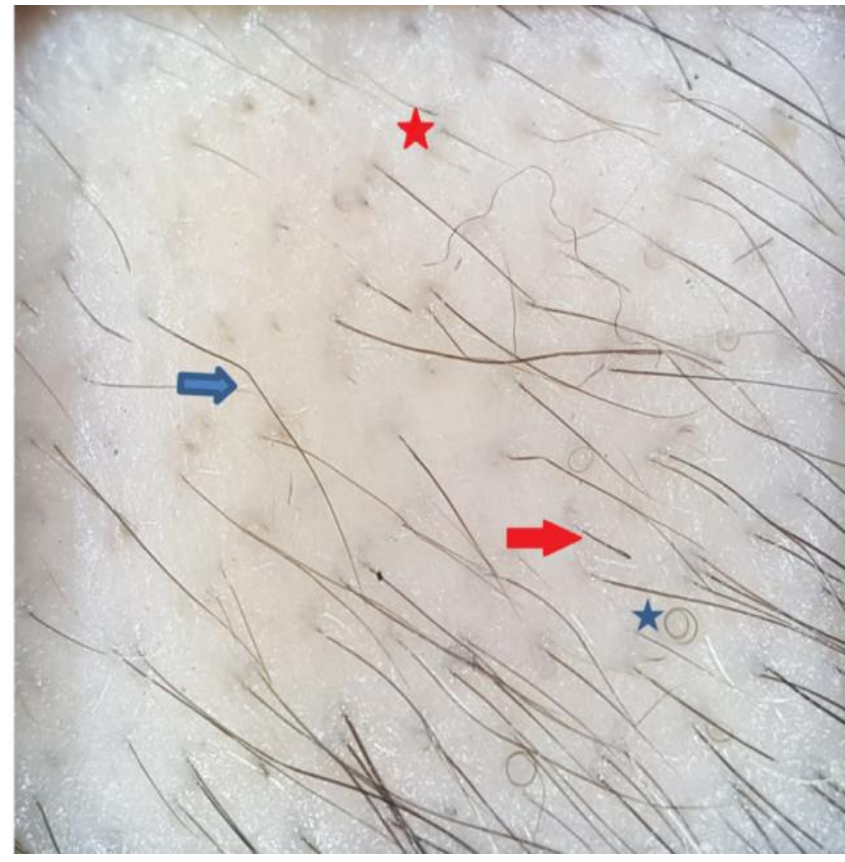

Figure 2. Blue arrow shows coudability hairs, red arrow shows tulip hair, blue star shows pigtail hair, red star shows Short vellus hair.

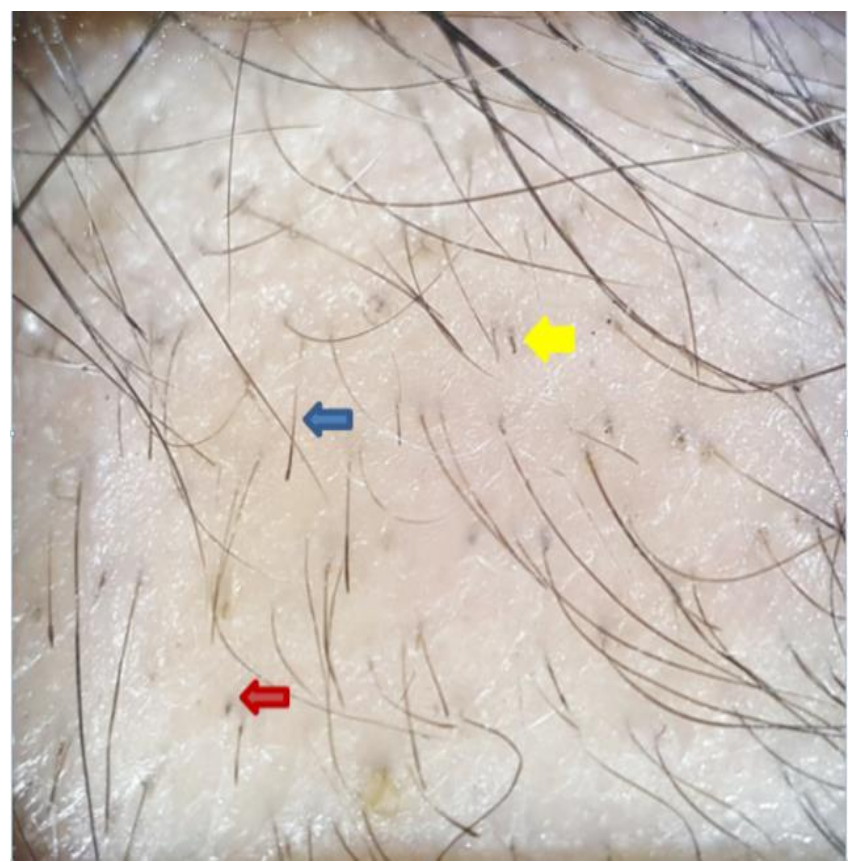

Figure 3. Blue arrow shows exclamation mark hairs, red arrow shows black dot, yellow arrow shows broken hairs. 
There was a significant correlation of YDs, BDs, Ehs, and BH with the severity of alopecia areata $(p<0.01)$, as shown by Table 3

Table 3. Correlation between dermoscopic findings and severity of alopecia areata

\begin{tabular}{|c|c|c|c|c|c|c|c|c|c|c|}
\hline $\begin{array}{c}\text { SEVERITY } \\
\text { OF AA }\end{array}$ & $\begin{array}{l}\mathrm{BDs} \\
\mathrm{N}(\%)\end{array}$ & $\begin{array}{l}\text { YDs } \\
\mathrm{N}(\%)\end{array}$ & $\begin{array}{l}\mathrm{BHs} \\
\mathrm{N}(\%)\end{array}$ & $\begin{array}{l}\mathrm{EHs} \\
\mathrm{N}(\%)\end{array}$ & $\begin{array}{l}\text { SVHs } \\
\mathrm{N}(\%)\end{array}$ & $\begin{array}{c}\mathrm{CH} \\
\mathrm{N}(\%) \\
\end{array}$ & $\begin{array}{c}\mathrm{TH} \\
\mathrm{N}(\%) \\
\end{array}$ & $\begin{array}{l}\text { PTH } \\
\mathrm{N}(\%) \\
\end{array}$ & $\mathrm{T} \mathrm{N}(\%)$ & $\begin{array}{c}\text { PS } \\
N(\%)\end{array}$ \\
\hline$S 1(n=65)$ & $21(32.3)$ & $20(30.7)$ & $13(20)$ & $12(18.4)$ & $18(27.6)$ & $7(10.7)$ & $3(4.6)$ & $7(10.7)$ & $9(13.8)$ & $5(7.7)$ \\
\hline$S 2(n=94)$ & $27(28.7)$ & $27(28.7)$ & $8(8.5)$ & $14(14.9)$ & $24(25.5)$ & $7(7.4)$ & $4(4.2)$ & 11(11.7) & $8(8.5)$ & $6(6.3)$ \\
\hline S3 $(n=25)$ & $10(40)$ & $19(76)$ & $9(36)$ & $5(20)$ & $8(32)$ & $2(8)$ & $1(4)$ & $4(16)$ & $2(8)$ & $2(8)$ \\
\hline S4 $(n=14)$ & $12(85.7)$ & $14(100)$ & $12(85.7)$ & $9(64.2)$ & $7(50)$ & 2(14.2) & $3(21.4)$ & $5(35.7)$ & $6(42.8)$ & $2(14.2)$ \\
\hline$S 5(n=11)$ & $1(9)$ & 11(100) & $1(9)$ & $3(27.2)$ & 0 & 0 & 0 & $1(9)$ & $2(18)$ & $1(9)$ \\
\hline$B 1(n=45)$ & $37(82.2)$ & $34(75.5)$ & $17(37.7)$ & 15(33.3) & $22(48.8)$ & $3(6.6)$ & $2(4.4)$ & $9(20)$ & $6(13.3)$ & $7(15.5)$ \\
\hline B2 $(n=11)$ & $1(9)$ & $11(100)$ & $1(9)$ & $3(27.2)$ & 0 & 0 & 0 & $1(9)$ & $2(18)$ & $1(9)$ \\
\hline$p$-value & $0.001^{\mathrm{s}}$ & $0.001^{\mathrm{s}}$ & $0.004^{s}$ & $0.009^{\mathrm{s}}$ & NS & NS & NS & NS & NS & NS \\
\hline \multicolumn{11}{|c|}{$\begin{array}{l}{ }^{*} p \text {-value is significant }(<0.05) \\
\text { BDs: black dots; YDs: yellow dots; BHs: broken hair; EHs: exclamation mark hairs; SVHs: short vellus hairs; } \\
\text { CH: coudability hairs; TH: tulip hairs; PTH: pigtail hair; T: telangiectasia; PS: perifollicular scaling; } \mathrm{S} \text { : } \\
\text { significant } p \text {-values; NS: nonsignificant } p \text {-values. }\end{array}$} \\
\hline
\end{tabular}

Nails involvement was seen in 28 patients in the current study, the duration of nails involvement was ranged from 1 to 17 years with a mean of $4 \pm 3.7$ years. Nails pitting were found in 21 patients, trachyonychia in 4 patients, while longitudinal striation was only seen in 3 patients. Nail changes were correlated with disease severity with $p$-value $<0.001$ as depicted in Table 4 .

Table 4. Correlation between clinical patterns of alopecia areata and nail involvement.

\begin{tabular}{|l|l|l|l|}
\hline $\begin{array}{l}\text { PATTERNS OF } \\
\text { AA }\end{array}$ & $\begin{array}{l}\text { NAIL CHANGES } \\
\text { PRESENT }\end{array}$ & $\begin{array}{l}\text { NAIL CHANGES } \\
\text { ABSENT }\end{array}$ & $\begin{array}{l}\text { TOTAL NUMBER OF THE } \\
\text { PATIENTS }^{*}\end{array}$ \\
\hline Localized Patchy & 4 & 58 & 64 \\
\hline Multiple patchy & 8 & 114 & 122 \\
\hline Ophiasis & 2 & 16 & 18 \\
\hline Totalis & 5 & 9 & 14 \\
\hline Universalis & 10 & 1 & 11 \\
\hline P-VALUE* & $0.001^{\text {s }}$ & $0.001^{\text {s }}$ & \\
\hline \# Patient may had more than one clinical pattern. & \\
\hline
\end{tabular}

The only significant correlation $(p<0.01)$ with the clinical variants of alopecia areata are seen in YDs, BHs, and EHs (Table 5). YDs were found in all patients of alopecia totalis and universalis, while BHs and EHs were found in $85.7 \%$ and $64.2 \%$ of the patients of alopecia totalis, respectively. Other dermatoscopic findings according to clinical variants are seen in Table 5. 
Table 5. Correlation between dermoscopic findings and patterns of alopecia areata.

\begin{tabular}{|c|c|c|c|c|c|c|}
\hline $\begin{array}{l}\text { DERMOSCOPIC } \\
\text { FINDINGS }\end{array}$ & $\begin{array}{l}\text { LOCALIZED } \\
\text { PATCHY } \\
n=62, N(\%)\end{array}$ & $\begin{array}{l}\text { MULTIPLE } \\
\text { PATCHY } \\
n=122, N(\%)\end{array}$ & $\begin{array}{l}\text { OPHIASIS } \\
n=34^{\#}, N(\%)\end{array}$ & $\begin{array}{l}\text { TOTALIS } \\
n=14, N(\%)\end{array}$ & $\begin{array}{l}\text { UNIVERSALIS } \\
\mathrm{n}=11, \mathrm{~N}(\%)\end{array}$ & $\begin{array}{l}P- \\
\text { VALUE }\end{array}$ \\
\hline BDs & $21(33.8)$ & $37(30.5)$ & 10(29.4) & 12(85.7) & 1(9) & $0.57^{\mathrm{NS}}$ \\
\hline YDs & $20(32.2)$ & $46(37.7)$ & $17(50)$ & $14(100)$ & 11(100) & $0.001^{\mathrm{S}}$ \\
\hline $\mathrm{BHs}$ & $11(17.7)$ & 17(13.9) & $9(26.4)$ & $12(85.7)$ & $1(9)$ & $0.011^{\mathrm{S}}$ \\
\hline EHs & $15(24.1)$ & $16(13.1)$ & $7(20.5)$ & $9(64.2)$ & $3(27.2)$ & $0.012^{S}$ \\
\hline SVHs & $18(29)$ & $32(26.2)$ & $7(20.5)$ & $7(50)$ & $0(0)$ & $0.46^{\mathrm{NS}}$ \\
\hline $\mathrm{CH}$ & $7(11.3)$ & $9(7.3)$ & $4(11.7)$ & $2(14.2)$ & $0(0)$ & $0.71^{\mathrm{NS}}$ \\
\hline TH & $3(4.8)$ & $5(4.09)$ & $1(2.9)$ & $3(21.4)$ & $0(0)$ & $0.58^{\mathrm{NS}}$ \\
\hline PTH & $7(11.2)$ & 15(12.3) & $6(17.6)$ & $5(35.7)$ & 1(9) & $0.17^{\mathrm{NS}}$ \\
\hline $\mathrm{T}$ & $8(12.9)$ & $14(11.4)$ & $6(17.6)$ & $4(28.5)$ & $1(9)$ & $0.57^{N S}$ \\
\hline PS & $4(6.4)$ & $8(6.5)$ & $3(8.8)$ & $2(14.2)$ & $1(9)$ & $0.68^{\mathrm{NS}}$ \\
\hline \multicolumn{7}{|c|}{$\begin{array}{l}{ }^{*} \mathrm{p} \text {-value is significant }(<0.05) \\
\text { BDs: black dots; YDs: yellow dots; BHs: broken hair; EHs: exclamation mark hairs; SVHs: short vellus hairs; } \\
\text { CH: coudability hairs; TH: tulip hairs; PTH: pigtail hair; T: telangiectasia; PS: perifollicular scaling; }{ }^{\text {s: }} \text {; } \\
\text { significant } p \text {-values; }{ }^{\text {NS. }} \text { : nonsignificant } p \text {-values. } \\
\text { \# Patient may had more than one clinical pattern. }\end{array}$} \\
\hline
\end{tabular}

\section{DISCUSSION}

Alopecia areata is one of the differential diagnoses of non-cicatricial alopecia and the diagnosis can be missed by other hair disorders, however, dermatoscopy which is a simple and noninvasive tool can help to reach a final diagnosis ${ }^{5}$. In the present study, most of the patients were in their second and third decades of life with male predominance, multiple patches of alopecia areata were the most common clinical pattern of the disease that affected more than half of the patients. These results are consistent with other studies ${ }^{7,8}$. Regarding scalp severity, S2 grade of severity represented $45 \%$ of the patients, followed by Grade $\mathrm{S} 1$ in $31 \%$ of patients, these findings are also documented in other studies ${ }^{12,13}$.

There are several dermoscopic signs of alopecia areata including YDs, BDs, SVHs, EHs, and BHs $(8,9,14)$. YDs were the commonest dermatoscopic sign noticed in this work. YDs were seen as yellow to yellow-pinkish hue, uniform in color, round, or polycyclic dots that vary in size. They represented an accumulation of keratinous material and sebum in the distended hair orifices. YDs were also noticed in other hair disorders ${ }^{14}$. The incidence of YDs in this research was 43.5 percent, which is similar to other studies 15,16 , however, other workers found a higher incidence of YDs ${ }^{8,9}$. The low frequency in this work might be attributed to the skin tone of the patients, different cleaning habits, and the type of dermatoscopy used since other researchers used an advanced dermatoscopy with a magnification of $x 32$ and $\times 140^{8}$.
Black dots were seen as destructed hair in the hair follicle orifices in 34 percent of the studied patients, similar to other workers ${ }^{16}$. However, other studies showed a higher incidence of BDs in patients who had type III and VI skin ${ }^{8,15}$. This result might be due to that BDs could not be seen easily in white individuals and cuticle resistance 8,15

In the present study, BHs were shown in about $86 \%$ of the patients who scored Grade S4, while Grade S2 only $8 \%$ of the patients which gave an indicator for disease severity. Some studies showed similar results ${ }^{9,10,12}$.

Exclamation marks hair (tapering hairs) represented as an acute phase of the disease, usually seen as fractured hair with a frayed thicker distal end and narrow proximal shaft 9 . In this study, EHs might be correlated with disease severity since they were noticed in about two-thirds of the cases who scored Grade S4 severity. Other studies revealed that tapering hairs didn't correlate with disease severity ${ }^{7,16}$.

Short vellus hairs are thin non-pigmented small hair which indicates regrowth of the hair and remission of the skin disease. In the current study, only $27 \%$ of the cases had SVHs, such a low frequency may be due to most of the patients examined before receiving treatment. These results were consistent with other workers ${ }^{9}$.

Pigtail hairs are thin coiled regrowing hairs that fall in few weeks ${ }^{10}$. In the current research, about $13 \%$ of the cases had PTHs, this result is consistent with other studies ${ }^{10,17}$. 
Coudablity hairs are observed on other hair disorders and presented as normal looking-hair that can easily kink when bent and applying inward pressure ${ }^{18}$. About $9 \%$ of the cases of this study had $\mathrm{CHs}$. CHs also correlated with the severity of the disease ${ }^{18}$. This study failed to find such a correlation due to the low incidence $(9 \%)$ of this sign among cases.

Telangiectasia was seen in $13 \%$ of the present patients in the form of arborizing and tortuous blood vessels. These results might be due to the use of topical and intralesional steroid. This result was also seen in other studies ${ }^{7}$.

Tulip hairs were seen mainly in trichotillomania as diagonal fractures of the hair shaft ${ }^{7}$

This study revealed $5 \%$ of the individuals had THs, with a lower frequency than other studies $?$.

Perifollicular scales were noticed in $7 \%$ of our patients, this might be due to concurrent scaly disease affect the scalp (psoriasis, tinea capitis, frontal fibrosing alopecia, and seborrheic dermatitis) and irritation from topical treatments. Other studies had a higher frequency of PS ${ }^{7}$.

Nail involvement was seen in about $14 \%$ of our patients, nearly half of them suffered from alopecia universalis and totalis for a long duration. This study found a correlation between nail changes and clinical varients of alopecia areata. These results go parallel with other studies ${ }^{3,8}$.

This study revealed different dermatoscopic findings of alopecia areata and their correlation with clinical patterns of the disease. YDs were seen in all patients with alopecia totalis, universalis, and nearly half of patients who suffered from ophiasis. Since, YDs correlated with disease severity, such association of YDs with alopecia totalis, universalis, and ophiasis were reasonable. These results were reported in other studies ${ }^{9,15}$. BHs and EHs were mostly seen in patients who had alopecia totalis and also were correlated with the clinical patterns of the disease, similar results were seen in other studies ${ }^{9,16}$.

Regarding scalp severity, this study found that YDs, BDs, BHs and, EHs, were markers for disease severity. YDs and BDs were correlated with scalp severity according to other studies ${ }^{7,12}$. $\mathrm{BHs}$ were also correlated with disease severity, the same result displayed by other researchers 7 . However, other studies noticed that $\mathrm{BHs}$ were markers for disease activity ${ }^{9,16}$.

This study noticed a correlation between EHs and disease severity, other workers noticed that EHs were associated with active disease ${ }^{16}$. Other studies failed to found a correlation with either disease activity or severity ${ }^{8,17}$. Other studies noticed that SVHs had a negative correlation with disease severity ${ }^{12,16}$ but in this study, we didn't notice such a correlation due to most of the patients didn't receive treatment.

In conclusion, dermatoscopy is a useful tool that can reveal several signs which are helpful in the clinical diagnosis and prognosis of alopecia areata. YDs, BHs and, EHs are correlated with clinical patterns of the disease. YDs, BDs, EHs, BHs, and nail changes are markers for the severe form of the disease.

\section{Limitation of The Study}

The uneven distribution of patients according to clinical varieties and SALT score was a drawback of our research. Similarly, the sample size for comparing certain variables like exclamation mark hairs, coudability hairs, and pigtail hairs was small.

\section{Ethical Issues}

The present study was approved by the Medical Research Ethics Committee, College of Medicine, University of Mosul, and Ninevah Health Directorate. Additionally, written informed consent was obtained from all patients before the examination.

\section{Acknowledgment}

This study was supported by College of Medicine, University of Mosul, and Ibn Sina Teaching Hospital, Mosul, Iraq.

\section{REFERENCES}

1.Pratt $\mathrm{CH}$, King LE Jr, Messenger AG, Christiano AM, Sundberg JP. Alopecia areata. Nat Rev Dis Primers. 2017;3:17011. Published 2017 Mar 16. doi:10.1038/nrdp.2017.11

2. Mirzoyev SA, Schrum AG, Davis MD, Torgerson RR. Lifetime incidence risk of alopecia areata estimated at $2.1 \%$ by Rochester Epidemiology Project, 1990-2009. J Invest Dermatol. 2014;134:1141-1142. doi: 10.1038/jid.2013.464.

3. Kasumagic-Halilovic E, Prohic A. Nail changes in alopecia areata: frequency and clinical presentation. $J$ Eur Acad Dermatol Venereol. 2009;23:240-241. doi: 10.1111/j.14683083.2008.02830.x

4.Blum, A., Kreusch, J., Stolz, W., Haenssle, H., Braun, R., Hofmann-Wellenhof, et al. Dermatoskopie bei malignen und benignen Hauttumoren : Indikation und standardisierte Terminologie [Dermoscopy for malignant and benign skin tumors : Indication and standardized terminology]. Hautarzt. 2017;68(8):653-673. doi:10.1007/s00105-017-4013-5

5.Lallas, A., Kyrgidis, A., Tzellos, T. G., Apalla, Z., Karakyriou, E., Karatolias, A., et al. Accuracy of dermoscopic criteria for the diagnosis of 
psoriasis, dermatitis, lichen planus and pityriasis rosea. $\mathrm{Br} J$ Dermatol. 2012;166(6):1198-1205. doi:10.1111/j.1365-2133.2012.10868.x

6. Al-Refu K. Clinical Significance of Trichoscopy in Common Causes of Hair Loss in Children: Analysis of 134 Cases. Int J Trichology. 2018;10(4):154-161. doi:10.4103/ijt.ijt_101_17

7. Bains P, Kaur S. The Role of Dermoscopy in Severity Assessment of Alopecia Areata: A Tertiary Care Center Study. J Clin Aesthet Dermatol. 2020;13(4):45-50.

8. Mane M, Nath AK, Thappa DM. Utility of dermoscopy in alopecia areata. Indian $J$ Dermatol. 2011;56(4):407-411. doi:10.4103/0019-5154.84768

9. Mahmoudi H, Salehi M, Moghadas S, Ghandi N, Teimourpour A, Daneshpazhooh $M$. Dermoscopic Findings in 126 Patients with Alopecia Areata: A Cross-Sectional Study. Int $J$ Trichology.

2018;10(3):118-123. doi:10.4103/ijt.ijt_102_17

10. Guttikonda AS, Aruna C, Ramamurthy DV, Sridevi K, Alagappan SK. Evaluation of Clinical Significance of Dermoscopy in Alopecia Areata. Indian J Dermatol. 2016;61(6):628-633. doi:10.4103/0019-5154.193668

11. Olsen EA, Hordinsky MK, Price VH, Sperling L, Whiting DA, Norris D. Alopecia areata investigational assessment guidelines--Part II. National Alopecia Areata Foundation. J Am Acad Dermatol. 2004;51(3):440-447. doi:10.1016/j.jaad.2003.09.032

12. Bapu NG, Chandrashekar L, Munisamy M, Thappa DM, Mohanan S.. Dermoscopic findings of alopecia areata in dark skinned individuals: an analysis of 116 cases. Int J Trichol. 2014;6:156159. doi: $10.4103 / 0974-7753.142853$

13. Nikhil N., Mamatha P., Hanumanthayya K. A study of clinical and dermoscopic features in alopecia areata at a tertiary referral center. Int $\mathrm{J}$ Res Dermatol. 2020 Nov;6(6):744-749. doi: https://dx.doi.org/10.18203/issn.24554529.IntJResDermatol20204457

14. Lima CS, Lemes LR, Melo DF. Yellow dots in trichoscopy: relevance, clinical significance and peculiarities. An Bras Dermatol. 2017; 92(5): 724-726. doi: 10.1590/abd1806-4841.20176157

15. Hegde SP, Naveen KN, Athanikar SB, Reshme P. Clinical and dermatoscopic patterns of alopecia areata: a tertiary care centre experience. Int J Trichology. 2013;5(3):132-136. doi:10.4103/0974-7753.125608

16. Inui $S$, Nakajima $T$, Nakagawa $K$, Itami $S$. Clinical significance of dermoscopy in alopecia areata: Analysis of 300 cases. Int J Dermatol. 2008;47: 688-693. doi: 10.1111/j.13654632.2008.03692.x
17. Peter D, George L, Pulimood SA. Trichoscopic features of various types of alopecia areata in India: application of a hand-held dermoscope. Australas J Dermatol. 2013;54(3):198-200. doi:10.1111/j.1440-0960.2012.00942.x

18. Inui S, Nakajima T, Itami S. Coudability hairs: a revisited sign of alopecia areata assessed by trichoscopy [published correction appears in Clin Exp Dermatol. 2010 Jun;35(4):457]. Clin Exp Dermatol. 2010;35(4):361-365.

doi:10.1111/j.1365-2230.2009.03510.x 